\title{
A Comparative Approach Towards Ethnic Segregation Patterns in Belgian Cities Using Multiscalar Individualized Neighborhoods
}

Lena Imeraj ${ }^{1}$, Didier Willaert ${ }^{2}$, Helga A.G. de Valk ${ }^{3}$

${ }^{1}$ Interface Demography, Vrije Universiteit Brussel - Pleinlaan 2, PL5 2.17, 1050

Brussels, +32 261481 24, Lena.Imeraj@vub.be [orcid.org/0000-0001-6942-2584]

${ }^{2}$ Interface Demography, Vrije Universiteit Brussel - Pleinlaan 2, PL5 2.19, 1050

Brussels, +32 261481 30, Didier.Willaert@vub.ac.be

${ }^{3}$ Netherlands Interdisciplinary Demographic Institute (NIDI)/ KNAW/ UoG Population

Research Centre - P.O. Box 11650, NL-2502 AR The Hague, +31 7035652 00,

valk@nidi.nl

All correspondence to:

Lena Imeraj

Vrije Universiteit Brussel, Department of Sociology - Interface Demography

Pleinlaan 2 PL5 2.17, 1050 Brussels, Belgium

Email: Lena.Imeraj@vub.be 


\begin{abstract}
Levels of spatial segregation in Western European cities are persistent over space and time. To demonstrate the degree or appearance of spatial segregation, most studies on urban residential patterns still rely on fixed spatial units, aspatial measures and single scales. However, a spatial or temporal comparison of patterns and levels of segregation based on such units or metrics is not without problems. To that end, this paper takes an explicit geographic approach and considers individualized neighborhoods using EquiPop-software, allowing various scales. Using the $k$-nearest neighbors for all individuals increases international comparability and facilitates interpretation, so far often hampered in segregation research. This multiscalar, multigroup comparative approach on ethnic urban geographies - using Belgium as a case study - provides an empirical illustration of a valuable method and tool applicable in segregation research, thereby furthering the comprehension of the increasingly diverse urban geographies and building on emerging work in the US, Europe and beyond.
\end{abstract}

Keywords: ethnic segregation, EquiPop, individualized neighborhoods, urban areas, Belgium, census data 


\section{Introduction}

The continuous rise in and diversification of Europe's immigrant population over the past couple of decades has ushered the public and political concern regarding the integration of (new) migrant communities into host societies. These include political, economic and social challenges (de la Rica, Glitz, \& Ortega, 2015). The process of migrant integration occurs through a variety of social interactions and inter-ethnic encounters in numerous domains (van Ham \& Tammaru, 2016). Despite the relatively low levels of segregation in European cities compared to those in the US (Marcińczak, Musterd, van Ham, \& Tammaru, 2015), the lack of socio-spatial mobility opportunities resulted into more secluded immigrant communities in cities. The latter is often believed to hamper social, cultural, economic and political integration and participation (Musterd, 2003-2005). The ideal of ethnic (and social) mix has become popular among policy makers and various attempts have been made in order to translate the ideal into a variety of policies aimed at reducing ethnic concentration and encouraging intercultural contacts (for a typology of desegregation policies see Bolt, 2009). Critical evaluation of these policies and subsequent area-based programs, however, raises further question whether these interventions are suitable to tackle social urban issues related to ethnic concentration and segregation (Andersson \& Musterd, 2005; Bolt, 2009). By overemphasizing the neighborhood level, many of the implemented policies fail to acknowledge the complexity of residential context's influence on individual outcomes in multiple geographic and social dimensions (Galster, 2001; Sharkey \& Faber, 2014). Even when tackled at the neighborhood level, segregation could still be present at lower (streets/blocks) or higher spatial levels (specific areas of the city).

In the scientific literature a large variety of a-spatial measures, fixed spatial units (i.e. census tracts/blocks, neighborhoods, wards) and single-scale analysis was for long common. The extensive application of area-based aggregates with different population counts, surfaces and distributions, however, fails to capture the geographic complexity of segregation (Openshaw, 1984). Recent literature on residential (ethnic) segregation has widely acknowledged the importance of spatial scale in the measurement and understanding of segregation levels and patterns (Fowler, 2016; Reardon et al., 2008). This has generated a series of attempts to modify the quantitative representation of populations, neighborhoods and segregation indices in various ways. These include for example spatially weighted matrices that mirror the degree of contact between spatial subdivisions (Wong, 2004); kernel-based density estimates (O’Sullivan \& Wong, 2007); 
and multilevel approaches suitable for assessing multigroup and multiscale segregation simultaneously (Jones, Johnston, Manley, Owen, \& Charlton, 2015). Furthermore, in yet another approach different criteria of geographical distance and density are used to construct circular, egocentric neighborhoods after which indices that reflect the separation between groups at various scales can be calculated (Reardon et al., 2008). Besides the fact that these new approaches can better capture the complexity of the urban structure and the processes that shape urban geography, they have also generated a fundamental debate revolving around methods and interpretation of segregation patterns and levels over time and space.

In this paper, we aim to address these issues by applying an individualized neighborhood approach based on population size (Östh, Clark, \& Malmberg, 2015; Östh, Malmberg, \& Andersson, 2014). By focusing on measures of population composition that refer to populations of similar size, we attempt to unravel and compare ethnic geographies across cities, scales and migrant populations. We focus on the case of Belgium, a country with a long-standing migration history similar to many north-western European countries (Van Mol \& de Valk, 2016). Since the majority of the migrant population is concentrated in urban areas, we study ethnic segregation levels of the five largest Belgian urban areas. Our spatial analysis, using comprehensive 2011 administrative census data, focuses on first generation migrants in Brussels, Antwerp, Ghent, Liège and Charleroi. To our knowledge, this is the first attempt to adopt a multiplace, multigroup and multiscalar comparative approach in the Belgian context and, thus, goes beyond relying on fixed spatial units to measure segregation. The goal of this paper is to achieve a better understanding of the extent to which various scales lead to different ethnic geographies and segregation levels. By focusing on the case of Belgian urban areas, we aim to provide evidence for a more generalized approach which could be further applied in other contexts.

\section{Geography, measurement and comparability of ethnic segregation}

Segregation is an inherently geographical phenomenon. However, often the various urban-specific population compositions and geographic dispersion or local variation within cities are not sufficiently captured by traditional segregation measures, and thereby ignore the spatiality of segregation. Spatial measures that focus on local areas within urban areas merit explicit attention (Brown \& Chung, 2006). Even so, these local measures do not necessarily take into consideration the multiscalar nature of segregation, 
for which literature provides manifold illustrations (e.g. Johnston, Forrest, Jones, \& Manley, 2016; Lee et al., 2008; Reardon et al., 2008). Measuring spatial fragmentation based on predefined areal units is confronted with the Modifiable Areal Unit Problem (MAUP), that is, issues concerning zoning and aggregation of data (Openshaw, 1984). Comparability of segregation patterns and measurements is far from straightforward since the resulting measures depend on how these fixed areas are defined.

The divergence between cities' population composition and structure makes interurban comparison of ethnic segregation even more difficult to interpret. In the case of Belgium, the urban expansion of medieval trading towns since the $19^{\text {th }}$ century was accompanied with a steady population growth, though, at different rates for the various cities. The diversity in industrial and economic developments led to a divergent spatial expansion due to varying mobility patterns (Van der Haegen, Brulard, Kesteloot, \& Vanneste, 1992). The dissimilar urban development resulted in quite distinctive urban structures, with regards to local economies, urban planning, housing markets, etc. As a consequence, ethnic groups are unevenly presented and distributed across various urban areas (Calliez, 2009). The different urban, institutional and structural frameworks as well as ethnic-specific spatial patterns remain under-researched so far and, therefore, encourage to use a multiscalar and explicit geographic approach to improve our understanding of these phenomena.

In this paper, we start from the concept of 'bespoke' neighborhoods (Bolster et al., 2007; MacAllister et al., 2001) and 'threshold analysis' (Johnston, Poulsen, \& Forrest, 2002-2004). Segregation patterns are analyzed using segregation measures based on individualized neighborhoods defined by the population size (Östh et al., 2015). The egocentric scalable neighborhoods, which act as our basic spatial units to compute measures of ethnic segregation, have not been applied to Belgium so far.

Starting with individualized neighborhoods we apply two segregation measures. First, we refer to the Location Quotient (LQ) (Brown \& Chung, 2006), which allows studying ethnic sorting processes and the resulting urban landscape from a more local point of view, while accounting for urban-specific population composition. In portraying "the concentration-evenness dimension" 1 (Brown \& Chung, 2006, p. 129, derived from Massey \& Denton, 1988), the LQ aids to better reveal the complexity of ethnic geographies and points to outliers that indicate spatial trends of ethnic over- or underrepresentation. The use of scalable egocentric neighborhoods allows for the computation of abundant scale-variant LQs, that enable us to explore the susceptibility of 
spatial outliers to scale. No single index up to date, however, was able to capture all aspects of segregation. To identify the clustering-exposure dimension of ethnic segregation withal, we therefore rely on the Spatial Isolation index (SI). This dimension of segregation refers to the extent to which a group shares a neighborhood with similar others; hence, groups and people are geographically represented in a cluster of either low or high exposure (Brown \& Chung, 2006; Massey \& Denton, 1988). The use of individualized neighborhoods allows the evaluation of exposure at various scales, that is "the probability of encountering representatives for different population groups if individuals are chosen randomly from the buffer population" (Östh et al., 2015, p. 5).

Extensive research on neighborhoods and localities have addressed the issue of

places being a function of various mechanisms that simultaneously manifest itself at different scales (Ainsworth, 2002; Fowler, 2016; Galster, 2001). Social processes and relevant interactions occur at fine-grained levels between individual actors within the experienced neighborhood or immediate residential environment, as well as in the wider neighborhood or urban area. When studying ethnic segregation, one needs to account for these multiple scales, actors and residential locations.

\section{Ethnic and spatial diversity}

Ethnic diversity is a key feature of contemporary population change and increasingly complex ethnic geographies in urban areas (Catney, 2016). As the majority of the migrant population settle down in urban areas, the diversity of the urban population is self-evident (Zorlu \& Mulder, 2008). Like many European cities, Belgian urban regions face substantial social, ethnic and geographic discrepancies. In his interstate comparison of ethnic and socio-economic segregation in Europe, Musterd (2005) illustrates that observed levels of segregation in some Belgian urban localities are among the highest in Europe. Studies have documented the persistence of ethnic segregation in all major cities, but are believed to be most pronounced in the Brussels capital (e.g. Van Hamme, Wertz, \& Biot, 2011). However, since most of these studies are based on fixed spatial units ('statistical sectors' or neighborhoods as defined by Statistics Belgium), they suffer from composition problems and comparisons between cities are difficult to make.

The specific migration history and migrant settlement patterns at least partly determine the urban ethnic geographies in Belgium also today. Within the wide range of countries of origin and motives for migration to Belgium, there is a clear distinction between the wealthier immigrants and those who have not accumulated high levels of 
human or economic capital prior to migration (for an overview of Belgium's migration history see Appendix 1). The ethnic segregation literature stresses the role of individual and household resources (Bajari \& Kahn, 2005) and the ability to realize residential aspirations within specific (financial) constraints and opportunities (i.e. spatial assimilation [Massey, 1985]). In the Belgian context, it is mainly former labor migrants and migrants from less developed countries that are in a precarious situation due to the low socio-economic position at arrival. These groups experience difficulties entering (and staying in) the labor market and, as a result, obtain lower levels of income (Phalet \& Swyngedouw, 2003). Hence, these migrants face severe obstacles to social mobility, thereby hampering socio-economic, residential and cultural integration. Inevitably, lacking opportunities to realize their residential preferences contribute to the persistence of spatial disparities in terms of socio-economic and ethnic characteristics (Bailey, 2012). For those who face most barriers, settlement near co-ethnics might be(come) the dominant strategy to realize residential preferences (Tajfel \& Turner, 1979). This results in ethnic communities, rich in cultural-specific resources and accessible and plentiful information, making spatial integration superfluous to some extent.

Residential preferences are very heterogeneous and so is the spatial distribution of dwellings across urban space (Bajari \& Kahn, 2005). In the case of Belgium, because of the liberal private housing market and the well-nigh complete absence of social housing in urban areas, the availability of accessible and affordable housing has a major role in steering migrant populations towards certain neighborhoods (and explains their absence in others). This is in line with the top-down view of structural and institutional theories (allied to the place stratification model of Massey, 1985), which stress the role of institutional barriers and the existence of economic, social and political inequalities in reproducing/shaping residential segregation along ethnic (or social) lines.

The spatial appearance of residential sorting mechanisms is likely to depend on the size of the urban area, the available housing stock and the presence and characteristics of minorities. A direct test of the extent to which individual preferences and characteristics as well as institutional contexts have actually contributed to the observed urban geographies is impossible with the census data we use here. Nevertheless, we explore the spatial outcomes of the interplay between these determinants at various scales, considering that 'migrant origin' is a good proxy indicator of the opportunities and constraints people face in life. In this way our analyses can provide important insights into the spatial segregation of different migrant origin groups in diverse urban areas. It 
may serve as a stepping stone for future research looking into individual settlement decision-making processes by using other types of data.

\section{Data and Methodology}

The aim of this study is to evaluate ethnic geographies in five Belgian urban metropoles using individualized neighborhoods that explicitly allow for multiple scales. These individualized or bespoke neighborhoods are neighborhoods with varying size, centered around the individual location considering the $k$-nearest neighbors (Östh et al., 2015). Egocentric spatial contexts thus are defined by the composition and geographic distribution of a person's nearest neighbors. In order to compute the $k$-nearest neighbors, we use the EquiPop-software (Östh, 2014). This tool for handling geographical information allows the use of more detailed locations other than tracts, blocks or wards (or statistical sectors in the case of Belgium) and is suited for large datasets, such as census or register data. We use geocoded data from the administrative 2011 census (Statistics Belgium, 2015) for all individuals included in the full de jure population at the moment of the census (January $1^{\text {st }} 2011$ ). Our analyses focus on inhabitants of the five Belgian metropolitan cities; the Brussels-Capital Region² (BCR), the cities of Antwerp and Ghent situated in the Flemish region, and the cities of Liège and Charleroi in the Walloon region (see Figure 1 for their geographic location).

Figure 1. Geographic location of the five Belgian metropolitan cities.

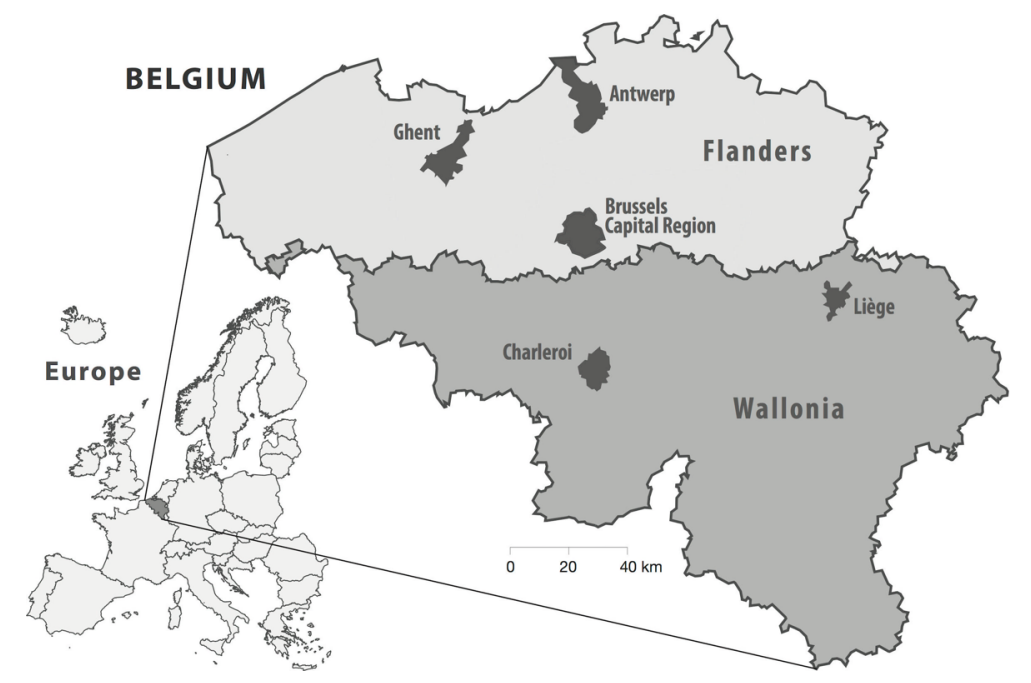

Different from the common procedure based on all individual distances, the software makes the analysis viable by transforming $(\mathrm{x}, \mathrm{y})$-coordinates into a geocoded 
matrix according to the $x$ - and $y$-values. In our case, for reasons of data availability, we were restricted to using small-scale areas ('grids'); grid cells have a spatial resolution of $200 \times 200$ meters, meaning that all coordinate details finer than 200 metric units are truncated. Grid cells without an individual are ignored. To allow pooling the nearest but not to the region belonging neighbors, the populations of adjacent suburban grid cells around each of the five cities are included (see Figure 2 for an illustration of Brussels).

Figure 2. Grids (200x200 meters) and bounding box (10km) of the Brussels-Capital Region.

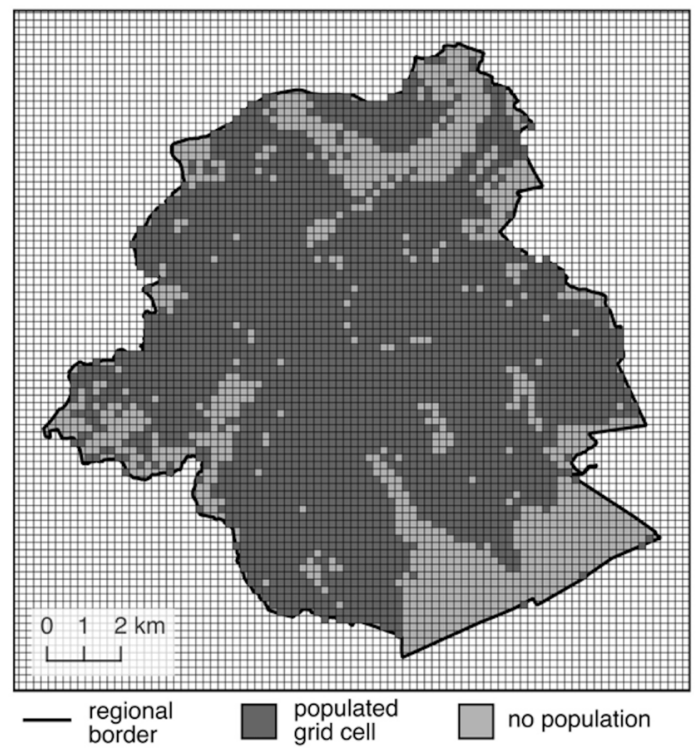

An iterative stepwise procedure estimates the spatial distribution of all population groups constructed by expanding a geographical buffer around each grid center until the buffer contains a predetermined number of neighbors $k$. Our interurban comparison considers population thresholds $k$ equal to $50,100,200,400,800,1,600 ; 3,200 ; 6,400$ and 12,800 . Thus, for every grid, nine differently sized bespoke neighborhoods come out of the procedure. The use of population criteria rather than a distance criterion assures divergent population densities being accounted for (Östh et al., 2015). The more detailed and visualized description of the software application is presented in Östh et al. (2014). Figure 3 presents the mean distance of each grid's expanded buffer containing the $k$ nearest neighbors for all urban areas. The mean distances for pooling the 50 and 12,800 nearest neighbors range from 102 to 169 meters and from 1,847 to 3,227 meters respectively. 
Figure 3. Mean distances of grids' expanded buffer containing the $k$ nearest neighbors, by metropolitan city, 1/1/2011.

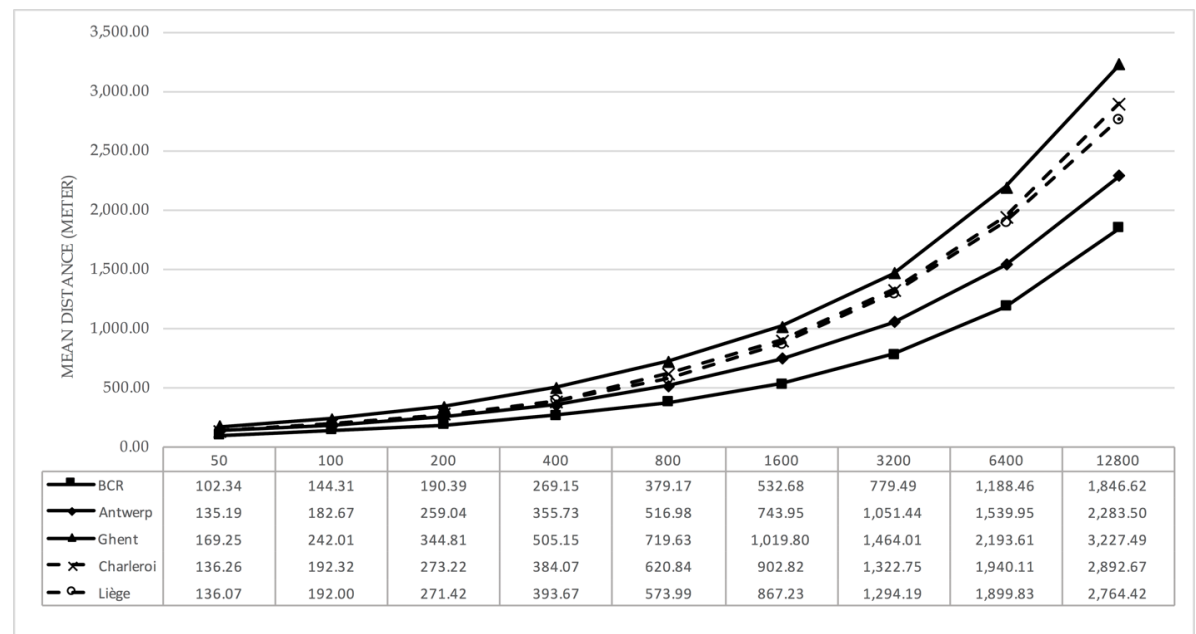

Source: 2011 Census, authors' calculations using Equipop

In a second step, ethnic segregation in bespoke neighborhoods is measured using two alternative spatial measures. First, the Location Quotient (LQ) reflects the concentration-unevenness dimension (Brown \& Chung, 2006) and for each neighborhood $i$ counting $k$ nearest neighbors is computed as

$$
L Q_{i, k}=\frac{\left(x_{i, k} / k\right)}{(X / T)}
$$

where $x_{i, k}$ and $k$ are, for example, the Moroccan and total population in neighborhood $i$ with $k$ nearest neighbors; $\mathrm{X}$ and $\mathrm{T}$ are the Moroccan and total population in the urban area. With seven different ethnic groups (see below) and nine differently sized egocentric neighborhoods, the residential context of each grid will be described in sixty-three different values in all five urban areas. Each LQ describes the share of, for example, Moroccans among the nearest 50,100,200,.., 12,800 neighbors relative to the share of Moroccans in the entire urban area. Hence, the LQ equals one in case the proportion of Moroccans in the egocentric neighborhood is consistent with the proportion of Moroccans for the urban area overall; LQ $>1$ indicates that there are proportionally more Moroccans among the $k$ nearest neighbors than in the urban area overall; LQ $<1$ if the share of Moroccans among the $k$ nearest neighbors is less than that for the urban area overall. GISsoftware was used to visualize the LQs for all ethnic groups, cities and population thresholds defined (315 maps). LQ-categories are based on the thresholds suggested by Brown and Chung (2006) and on the observed distribution of our data. LQ $\leq 0.85$ 
indicates an underrepresentation of an ethnic group, whereas LQ $\geq 1.20$ indicates a significant overrepresentation, respectively corresponding with one standard deviation below and above one.

Second, in line with Östh et al. (2015) and also considering the population threshold $k$, the Spatial Isolation (SI) index is computed as

$$
S I_{k}=\frac{\sum_{i=1}\left(x_{i, k}\right) * \frac{x_{i, k}}{k}}{\sum_{i=1}\left(x_{i, k}\right)}
$$

with $k$ being the number of nearest neighbors and $x_{i, k}$ the number of ethnic minority

members in area $i$ among the $k$ nearest neighbors. $\frac{x_{i, k}}{k}$ then equals the proportion of the ethnic population among the $k$-nearest neighbors of people living in area $i$. The SI measures the extent to which members of an ethnic minority are only exposed to one another. The aggregate SI gives the same expected probability of meeting a member of a subgroup, but as a population group average.

In this study, the definition of immigrant origin is based on the country of birth of a person (thus we cover only first-generation migrants). The indicator separates following countries or groups of countries of birth: (1) Belgium; (2) Southern Europe (Spain, Greece, Portugal, Italy, Malta, Cyprus); (3) Eastern Europe (Albania, Bulgaria, Hungary, Poland, Romania, Czech Republic, Slovakia, former Czechoslovakia, Russia + former USSR), Serbia, Croatia, Slovenia, Macedonia, Bosnia-Herzegovina $(+$ former Yugoslavia), Latvia, Estonia, Lithuania, Belarus; (4) Western European countries (Andorra, Germany (+ former East and West Germany), Austria, Denmark, Finland, France, UK, Luxemburg, Ireland, Iceland, Liechtenstein, Monaco, Norway, San Marino, Sweden, Switzerland, the Netherlands); (5) Turkey; (6) Morocco; and (7) the remaining countries, which mainly consist of countries in developing regions (Asia, Africa (except Morocco), Latin-America).

\section{Belgian metropolitan cities in a nutshell}

Table 1 presents socio-demographic characteristics of the urban populations in Belgium compared to the full population of the country. The total population on January $1^{\text {st }} 2011$ comprised 11,000,638 inhabitants, of whom $14.8 \%$ is foreign born. The share of foreign born was only $5.7 \%$ after World War II, showing the increased ethnic diversity in the country over the last 60 years $^{3}$. Between the five urban areas there is clear diversity as well as in the share of foreign-born: ranging from $17.9 \%$ in Ghent to $42.4 \%$ in the Brussels region. Overall however, foreign-born persons tend to be overrepresented in these large 
urban areas, particularly in Brussels (additional characteristics are provided in the lower part of Table 1 in the supplemental background information).

Table 1. Socio-demographic characteristics of the five metropolitan Belgian cities, 1/1/2011.

\begin{tabular}{|c|c|c|c|c|c|c|}
\hline & $\begin{array}{l}\text { BRUSSELS- } \\
\text { CAPITAL } \\
\text { REGION }\end{array}$ & ANTWERP & GHENT & LIÈGE & CHARLEROI & BELGIUM \\
\hline $\begin{array}{l}\text { TOTAL } \\
\text { POPULATION }\end{array}$ & $1,136,778$ & 498,473 & 248,358 & 195,965 & 204,150 & $11,000,638$ \\
\hline $\begin{array}{l}\text { POPULATION } \\
\text { DENSITY (INH. PER } \\
\text { SQUARE KM) }\end{array}$ & 7,044 & 2,437 & 1,590 & 2,824 & 2,000 & 360 \\
\hline $\begin{array}{l}\text { FOREIGN BORN } \\
(\%)\end{array}$ & 42.4 & 25.8 & 17.9 & 27.1 & 18.2 & 14.8 \\
\hline EU27 & 16.8 & 7.3 & 5.8 & 10.0 & 8.7 & 7.0 \\
\hline NON-EU27 & 12.6 & 9.9 & 6.0 & 8.8 & 5.4 & 3.7 \\
\hline $\begin{array}{l}\text { NON-BELGIAN } \\
\text { NATIONALITY (\%) }\end{array}$ & 32.3 & 17.9 & 12.0 & 18.9 & 15.0 & 10.5 \\
\hline $\begin{array}{l}\text { SEX RATIO } \\
\text { (FEMALE TO MALE) }\end{array}$ & 105.02 & 101.65 & 102.81 & 103.05 & 105.75 & 104.00 \\
\hline MEAN AGE & 37.5 & 39.8 & 40.0 & 40.5 & 40.0 & 40.8 \\
\hline $\begin{array}{l}\text { HIGHER } \\
\text { EDUCATION }(\%)^{2}\end{array}$ & 35.3 & 25.6 & 36.1 & 28.6 & 16.1 & 28.0 \\
\hline $\begin{array}{l}\text { UNEMPLOYED } \\
\text { AGED } 15-64(\%)^{3}\end{array}$ & 16.7 & 9.9 & 7.6 & 19.8 & 21.2 & 8.4 \\
\hline $\begin{array}{l}\text { STATISTICAL } \\
\text { SECTORS }\end{array}$ & 712 & 279 & 194 & 285 & 285 & 19,704 \\
\hline
\end{tabular}

Source: 2011 Census, Statistics Belgium

Notes:

${ }^{1}$ Includes refugees and asylum seekers, registered on 1/1/2011.

${ }^{2}$ Percentage of higher-educated in the population aged 20 and older.

${ }^{3}$ Percentage of unemployed in the labor force (employed and unemployed) aged 15 to 64

Since our detailed analyses provide a wide range of information at different levels, we only discuss the most remarkable findings on ethnic geographies and segregation (full details on all five cities, seven origin groups and nine scales are available upon request from the first author).

\section{Results}

\section{Ethnic geographies: a local and scalable perspective}

First we focus on the Location Quotients of the origin groups in all five cities, exploring differences in local ethnic representations relative to their overall presence in the respective city. LQ treats each neighborhood independently, hence illustrating the singleunit concentrations (Brown \& Chung, 2006). The use of egocentric neighborhoods allows the computation of the group-specific LQs for a wide range of scales, thereby to some extent identifying ethnic 'clusters' with an increasing scale. To avoid any ambiguities we 
will refer to 'ethnic concentrations' when exploring the geographic patterns revealed by the LQ at any scale.

Figure 4 shows the range of the computed LQs for all urban areas, all ethnic populations and all scales. Given our interest in spatial outliers, we focus on minimum (left panel) and maximum (right panel) values of the LQs rather than the mean values. Three important patterns are observed. First, little variation of minimum LQ values is noted at the lower end of the scale range, meaning that, with the exception of natives in all urban areas but Liège, every city has at least one neighborhood containing 50 nearest neighbors in which a particular ethnic group is entirely absent. In many cases, these findings can be extended to higher scale neighborhoods. In particular, for Turkish and Moroccan foreign-born, all urban areas have meso-scale neighborhoods with around 1,600-3,200 nearest neighbors (or even macro-neighborhoods in the case of Ghent) that contain no Turks or Moroccans. Second, albeit all ethnic populations are significantly overrepresented in at least one smallest scale neighborhood, Turkish minorities tend to be extremely overrepresented in the egocentric micro-neighborhoods compared to the other groups with LQ-values roughly between 20 and 40 (Moroccans in the case of Ghent). Even at the higher end of the scales, Turks and Moroccans tend to be concentrated (except in Charleroi), while most of the other group-specific LQs converge towards similar lower levels. The latter observation, brings us to a third point: ethnic LQs are susceptible to scale to a very different extent in all cities. To sum up, the under- or overrepresentation of particular ethnic populations relative to their presence in the urban areas overall, varies greatly. 
Figure 4. Location Quotients' minima (left panel) and maxima (right panel) by metropolitan city, by migrant origin population, and by $k$-nearest neighbors, $1 / 1 / 2011$

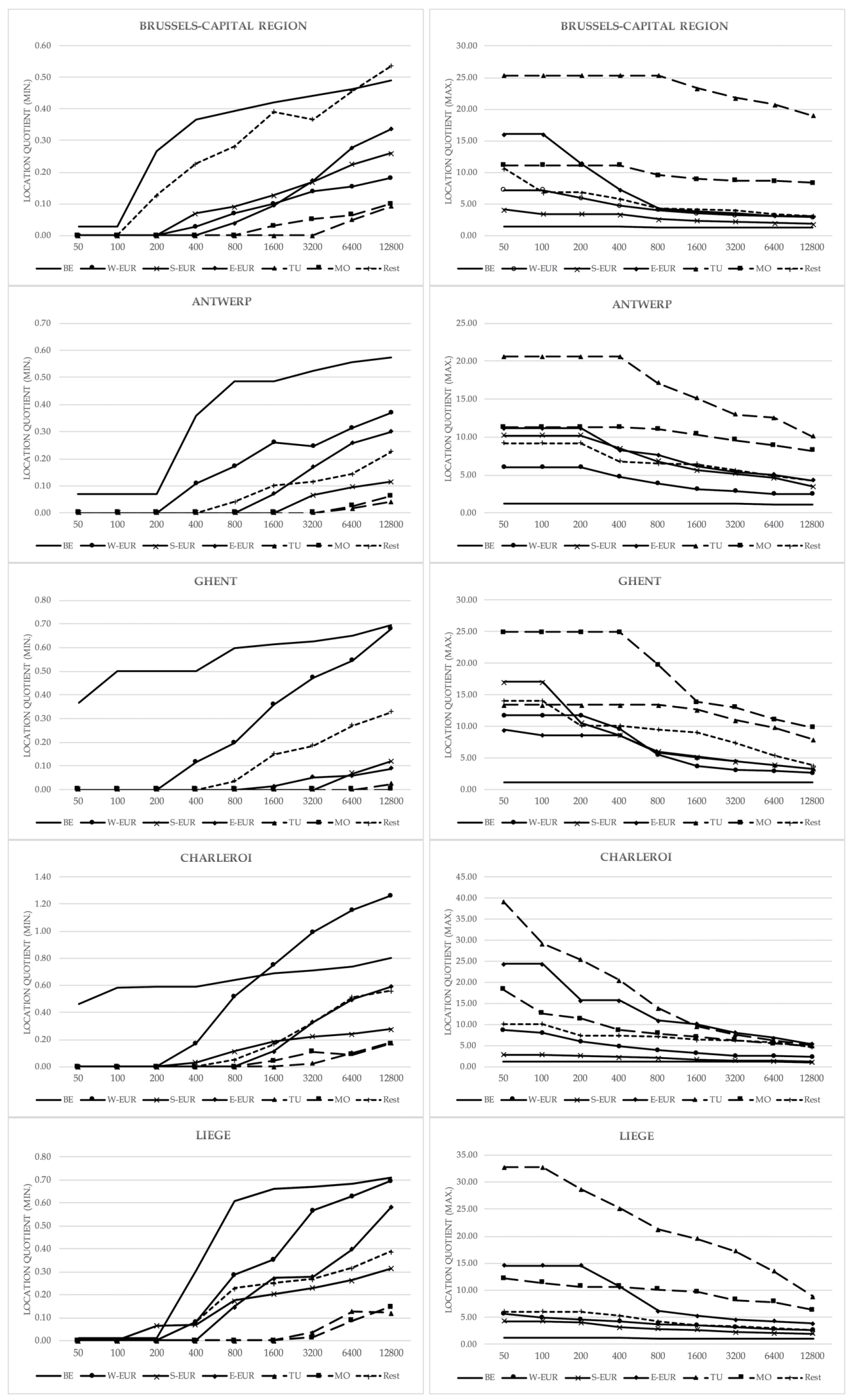

Source: 2011 Census, authors' calculations using Equipop 
These plots do, however, not provide information on the number of egocentric neighborhoods that significantly deviate from the normal trend in the comparison area, nor do they give insight into ethnic geographies. To provide an appreciation of the ethnic geographies and the outliers, Figures 5 to 7 map the LQs of ethnic minority groups for each of the grid cells (200 x 200 meters) computed for the $k$ nearest neighbors of an individual. The consideration of neighborhoods of equal population size, allows for a valid comparability that takes into account different compositions. As noted in the method section, we apply a categorization based on thresholds that indicate under- (LQ $\leq 0.85$ ) and overrepresentation (LQ $\geq 1.20$ ) of a migrant group.

Spatial concentrations of the different origin groups emerge in all urban areas, however, vary greatly between the different cities in terms of specific location within the urban area and the extent of over- or underrepresentation. A first illustration of this is given in Figure 5, showing the LQs of Turkish-born residents in Brussels, Ghent and Charleroi, considering the 50, 800 and 12,800 nearest neighbors respectively. The maps give a general overview of how widely Turks are distributed within the metropolitan areas, the degree to which they are concentrated in specific neighborhoods and the extent to which these concentration levels and patterns vary when using different scales. Spatial patterns point to neighborhood micro-segregation $(\mathrm{k}=50)$ for Turkish foreign-born in all cities. However, concentration areas appear more distributed in the case of Charleroi compared to Brussels and in particular Ghent. With an increasing $k$, meso- $(\mathrm{k}=800)$ and macro- $(\mathrm{k}=12,800)$ segregation becomes more pronounced. Clearly, in Ghent and Brussels, few areas outside these concentration areas contain a share of Turks similar to the general trend in the entire urban area, whether at a micro-, meso- or macro-level (indicated by the areas with $0.85 \leq \mathrm{LQ} \leq 1.20$ ). For different $k$-thresholds, scale seems to matter little, albeit the geographical pattern is smoothened as the user-defined scale increases. Turkish minority members hence are heavily concentrated into relatively few neighborhoods (red) and are entirely absent from many parts of the city (blue). This pattern is less pronounced in Charleroi, where more neighborhoods containing the 12,800 nearest neighbors show normal proportions of Turks compared to the city overall. Similar patterns are found for the Moroccan foreign-born (presented in Appendix 2). Both migrant populations to some extent seem to be condensed in the same urban macro-areas, thereby sharing the same meso- and macro-metropolitan space. Still, among the 50 
nearest neighbors there exists a considerable divergence in Turkish and Moroccan geography (e.g. in Ghent).

Figure 5. Spatial distribution of Location Quotients of Turkish foreign-born in the BrusselsCapital Region (BCR), Ghent and Charleroi, using individualized neighborhoods containing the 50, 800 and 12,800 nearest neighbors, 1/1/2011.

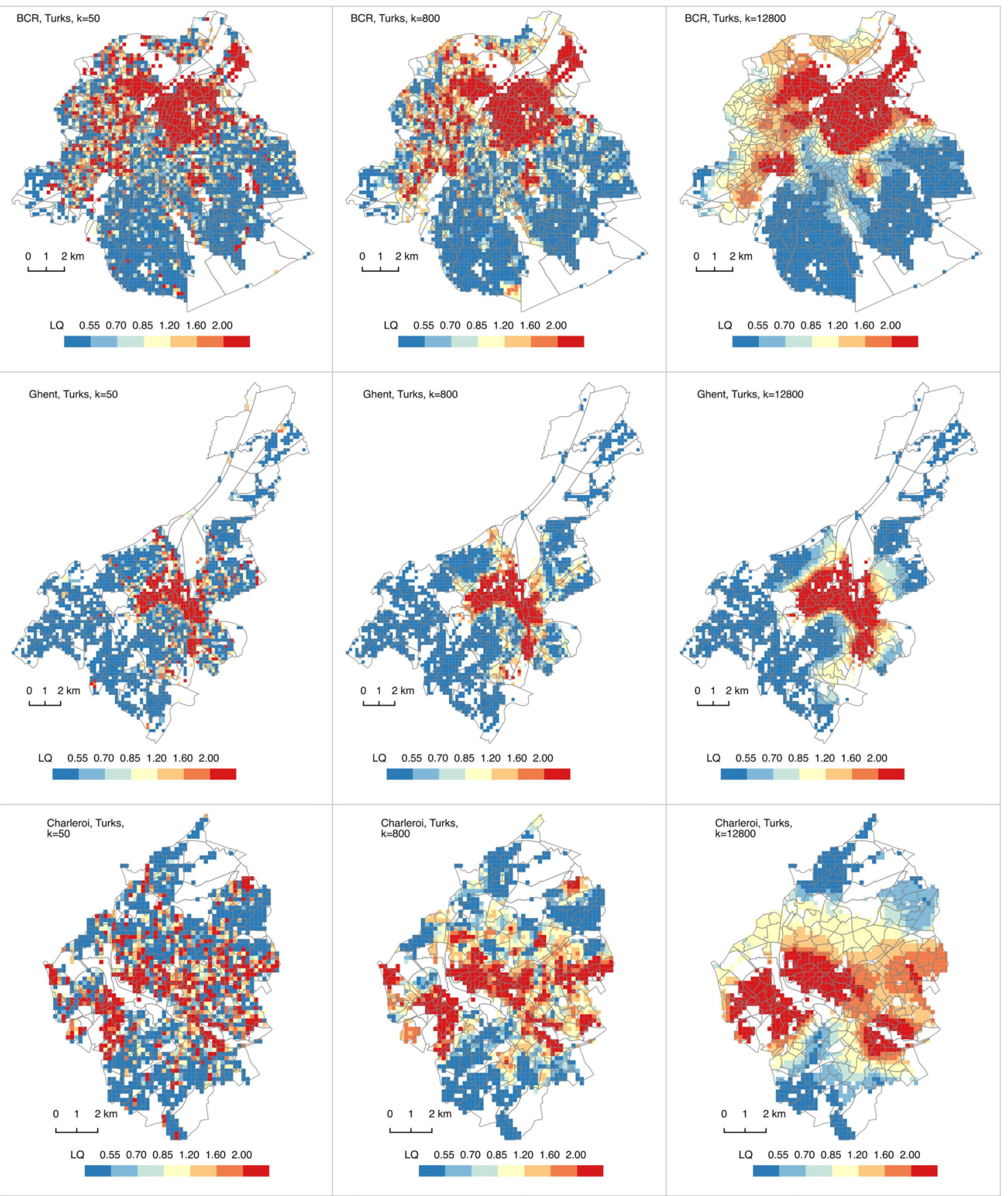

Source: 2011 Census, authors' calculations using Equipop 
Figure 6 presents the geographies of European populations in the Brussels capital, considering the 100, 3,200 and 12,800 nearest neighbors. These individualized neighborhoods illustrate how Western Europeans are more likely to live in the southeast of Brussels and are nearly absent in the northwestern part of the city, whatever scale we consider (Fig. 6, upper row). Foreign-born Turks and Moroccans in Brussels clearly do not share the same urban space with Western Europeans. This polarized pattern is not observed in the other cities. Antwerp, for example (see Appendix 3, upper row), elucidates a centroid pattern with pronounced concentrations of Western Europeans in the inner city. The spatial micro-concentration to a great extent resembles higher-scale geography, nevertheless, some micro-pockets of West-European gathering are discerned. The middle row of Figure 6 shows how Southern Europeans are much less concentrated compared to the average pattern in the Brussels area overall. Despite the appearance of some dense micro-areas among the 100 nearest neighbors, less pronounced concentrations are distinguished at meso- and macro-levels. Still, being significantly underrepresented in a large urban part (blue), Southern Europeans tend to have gravitated towards a particular macro-area in the city in which they are quite evenly distributed on a lower scale. Similar geographies are observed for Liège (Appendix 3, middle row). However, within these macro-areas of settlement, small ethnic enclaves are visible. Eastern Europeans (Fig. 6, bottom row) show high density areas at any scale. Although overrepresented in inner-city areas, this migrant population tends to be more spatially dispersed throughout the city at meso- and macro-levels, that is, less LQs are significantly below 0.85. Similar geographies are observed in Charleroi (Appendix 3, bottom row). 
Figure 6. Spatial distribution of Location Quotients of Western European, Southern European and Eastern European foreign-born in the Brussels-Capital Region (BCR), using individualized neighborhoods containing the $100,3,200$ and 12,800 nearest neighbors, $1 / 1 / 2011$.

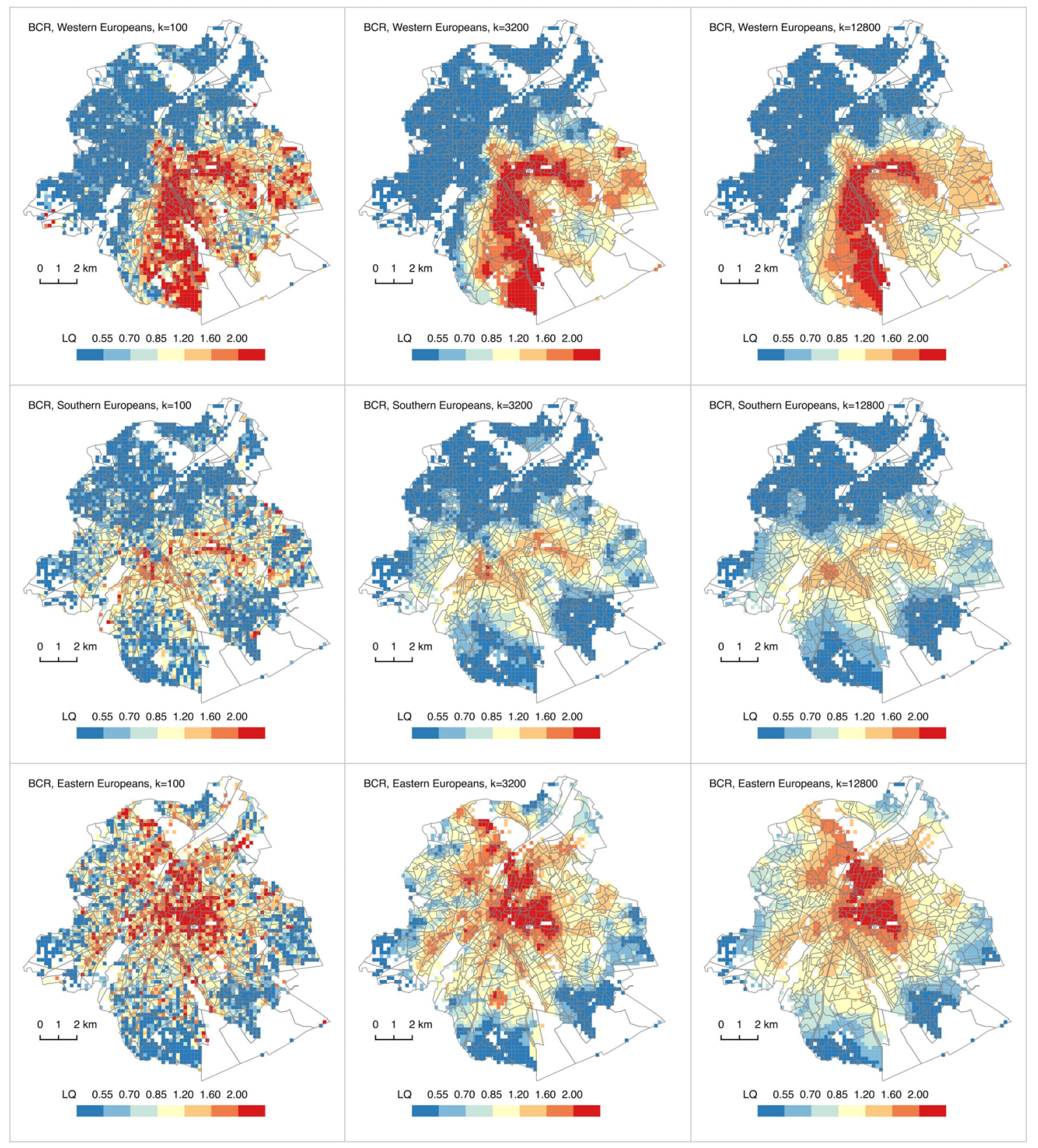

Source: 2011 Census, authors' calculations using Equipop

Migrant segregation is also generated by the residential patterns of the nativeborn. Figure 7 show the LQs of natives in the five cities considering the 6,400 nearest neighbors. The maps reveal that natives to a great extent are represented in the individualized neighborhoods similar to what would be expected relative to their presence in the entire urban area. They tend to avoid ethnic dense areas, often inner-city areas, 
where Turks, Moroccans and Eastern Europeans are significantly overrepresented (as illustrated above). This is most pronounced in the case of Brussels.

Figure 7. Spatial distribution of Location Quotients of natives in Brussels-Capital Region (BCR), Antwerp, Ghent, Charleroi and Liège, using individualized neighborhoods containing the 6,400 nearest neighbors, $1 / 1 / 2011$.

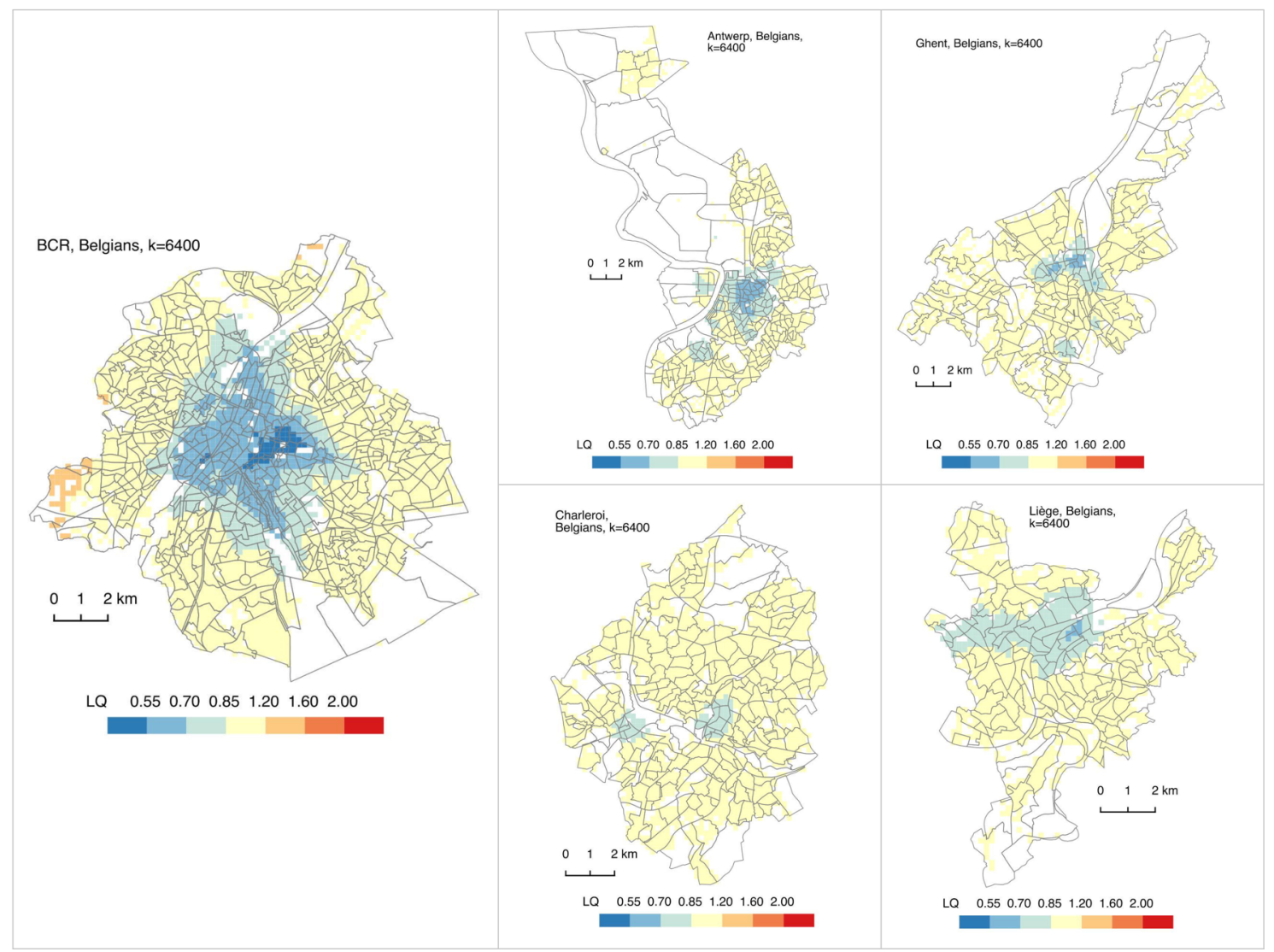

Source: 2011 Census, authors' calculations using Equipop

\section{Living isolated at various scales}

Figure 8 provides an overview of the scale susceptibility of the Spatial Isolation (SI) index, constructed for all origin groups, all scales and all cities. This measure portrays the clustering-exposure dimension of segregation. The SI indicates the probability of an individual to meet a person belonging to the same ethnic minority group among the $k$ nearest neighbors. Over all five cities, all seven ethnic minorities and all nine scales, spatial isolation of the Moroccan migrants in the Brussels-Capital Region - as a population average - is the highest, with the level of isolation of the category 'other' foreign-born following closely. The latter group similarly shows high probabilities of meeting an own-ethnic member within the nearest $k$ neighbors around him/her. The 
encounter of a co-member of this 'other' group is blurred given its highly heterogeneous composition - however mainly composed by migrants from the least developed countries. The SI index is the highest for Turks and Eastern Europeans in Ghent, though, the levels of isolation are comparable to those of Western Europeans in Brussels or Moroccans in Antwerp. Importantly however, these modest segregation levels may have a significant importance within their own societal context (Kaplan \& Woodhouse, 2005). Bearing in mind the principle of the Location Quotient, the meaning of being isolated perhaps should be interpreted relative to the isolation of other groups in the same urban area. For example, Turks and Eastern Europeans in Ghent and Southern Europeans in Charleroi stand out in particular compared to their co-citizens. Hence, their relative experience of isolation might be more pronounced than is the case of Moroccans in Brussels. Based on the geographic LQ distributions of these particular migrant population, we arrived at somewhat different conclusions however (see Appendix 4 for an illustration of the spatial distribution of LQs). The pronounced isolation of Turks in Ghent is observed from the LQ levels and the spatial embeddedness at any scale. For Southern Europeans in Charleroi, the few micro-concentrations and lacking meso- or macro-concentrations, contrast the relatively high SI. In addition to this and in line with the literature, isolation appears higher in bespoke neighborhoods that account only for a small number of nearest neighbors. The likelihood to encounter own group members decreases as the scale increases, albeit the magnitude of this decrease in spatial isolation is incongruous for the various migrant groups.

\footnotetext{
${ }^{1}$ The five dimensions were reduced to only two dimensions, i.e. concentration-evenness and clusteringexposure. Note other junctions are suggested, see for example Johnston, Poulsen, and Forrest (2007).

2 BCR is an administrative unit (corresponding to the NUTS 1 level) that consists of 19 municipalities.

${ }^{3}$ Source: Legal resident population by country of birth, from 1880 to 2008; Statistics Belgium, calculations by ADSEI (period 1880-1981) and GéDAP-UCL (period 1991-2008)
} 
Figure 8 . Spatial Isolation index by metropolitan city, by migrant origin group, and by $k$-nearest neighbors, $1 / 1 / 2011$.

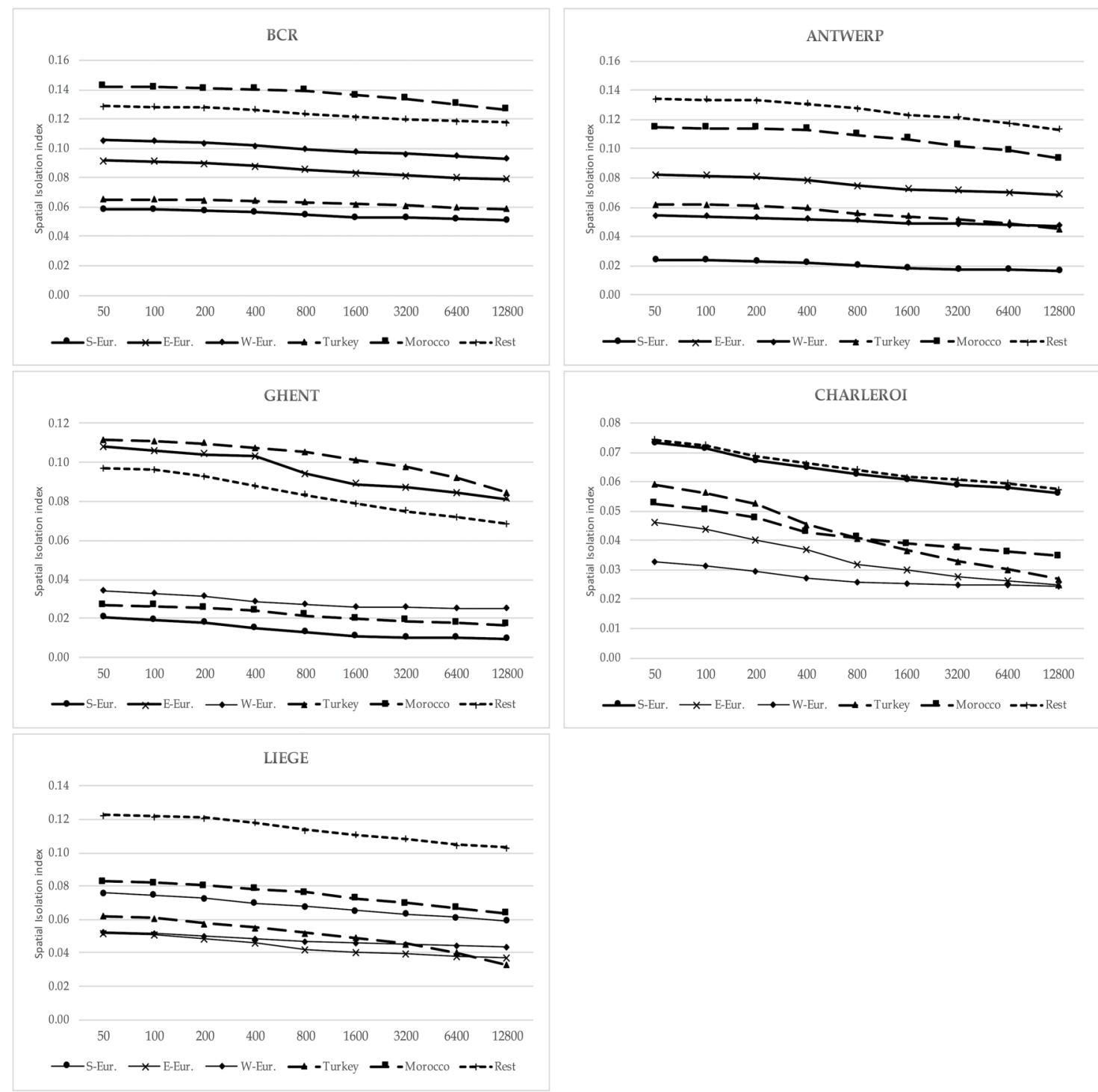

Source: 2011 Census, authors' calculations using Equipop

\section{Discussion and conclusion}

This study takes a geographic and multiscalar approach to compare ethnic segregation in five Belgian urban areas considering egocentric neighborhoods. Geocoded grid (census) data were used to compute aggregated spatial measures (Location Quotient and Isolation Index), based on individualized neighborhoods with user-defined population thresholds. In this way the paper addressed the current concerns on social cohesion and fragmentation in urban areas related to increasing diversity of European populations. Overall, our findings draw attention to the value of using easily interpretable segregation measures that account for complex geographies and divergent urban populations, while allowing 
for various scales. The results demonstrate that ethnic segregation may (or may not) exist at multiple levels at the same time. This suggests that the process of (growing) spatial polarization in cities is attributable to both individual and collective behavior, migrant group composition and histories to locations, and institutional agency within the broader economic, political, cultural and social context. If we want to understand the heterogeneous spatial outcomes and differential chances of meeting individuals belonging to different ethnic groups, the utilized approach appears to indicate that nearest neighbors and scalable neighborhoods are useful ways of providing more insight into these issues.

In part, the various spatial patterns reflect the extent to which spatially based attributes, that are differently valued by different population groups, are unequally distributed over space and cover locations of various size or scale (Galster, 2001). In line with van Kempen and Wissink (2014), we assume that these residential environments remain an important reality for everyday lives of people belonging to different groups and places. Of course, "sharing space does not always bring about the proximity of residence that constitutes places" (Kearns \& Parkinson, 2001, p. 2104) nor are personal networks inherently bound to a particular area (van Kempen \& Wissink, 2014). Importantly however, neighborhoods can be considered as places to establish contacts with nearby others. To that end, this paper has approached the concept of 'nearness' through neighborhoods based on one's nearest neighbors, rather than spatial distance or social distance (Kearns \& Parkinson, 2001). The use of egocentric neighborhoods to depict the presence or absence of people with particular characteristics as presented in this study, offers a powerful new framework for understanding how ethnic geographies and segregation vary. Our Belgian case-study shows the relevance of scale and space when drawing upon the general assumption that places and nearby people matter. This approach may be useful to study urban geographies in other European countries and beyond. Hence, the method provides a viable starting point to further explore how individual behavior and context-specific social opportunities and barriers at different levels shape residential outcomes of people and thus of social interactions in urban spaces. In the Belgian case the Brussels-Capital Region clearly stands out as being different. This may be related to the specific composition of the migrant population (including both a variety of non-western and European origins) and their migration history. The extent to which this also holds for other capitals across Europe can be discussed but at least warrants further comparative studies to point at similarities and differences. 
In our view, the complementary use of two segregation indexes proved highly useful as in this way we better capture the connection between urban-specific population compositions, geographic dispersion within cities and chances of meeting people with similar backgrounds. The Spatial Isolation index confirmed that low-scale isolation is well above the levels of isolation at meso- and macro-levels, for all minorities in all cities. This partly substantiates with earlier findings of Johnston et al. (2016), who found for Australia that most ethnic groups are more isolated at the micro- as well as the macrolevel than at the meso-scale. The extent to which isolation varies by scale is more outspoken for some groups and some cities (e.g. Turks and Eastern Europeans in Ghent, and Moroccans in Brussels) than it was for the others in our study. Isolation appears modest, however, sometimes in disagreement with the values of the Location Quotient. The index of Spatial Isolation, being measured on a city level, is not independent of the relative size of an ethnic group within the respective urban populations, nor does it explore the ethnic geographies that shape opportunities to encounter own-group members in the surrounding residential environment, regardless of the fact that we relied on scalable neighborhoods to compute the index.

In this paper we took a multiple comparative approach to explore ethnic geographies and testing theories of spatial segregation. The here applied method is extremely useful for studying spatial patterns at multiple scales from an ethnic- and location-specific point of view. It challenges traditional theories related to segregation and encourages to a more nuanced view on how different mechanisms interact in shaping segregation among different groups and localities. Segregation by disadvantage - or advantage in the case of more affluent migrants and natives - seems to be a major force in shaping ethnic geographies in Belgian cities. Overall, (dis)advantaged groups were found to be overrepresented in many small neighborhoods (around 50-100 nearest neighbors), located in particular segments (indicated by $k$-values above 3,200 ) of the city. Meanwhile, they are absent from other city segments. These patterns provide an illustration of how initial settlement areas expand as more recent migrants arrive, however, seemingly not altering the restraints bounding residential settlement. To get a better view on how residential segregation patterns change over generations and time, longitudinal data including sufficient first- and second-generation migrants, as well as their migration histories and socio-demographic characteristics, are needed. So far, data are not available to conduct this type of analyses. Our work does, however, show that generally the Turkish and Moroccan communities and less wealthy origin groups have 
ended up in the $19^{\text {th }}$ century areas of the Belgian cities, with the least attractive housing stock, that is, the cheapest, oldest and most poorly-equipped dwellings (Kesteloot \& Cortie, 1998). Nevertheless, there has been a firm increase in owner-occupation within the Turkish and Moroccan communities (Kesteloot \& Cortie, 1998). Homeownership is an investment that has a long-projected lifespan and is spatially fixed, making the neighborhoods of these emergency buyers very durable (Galster, 2001). This potentially new 'ethnic' segment of the housing market may reinforce self-selection of newly arrived migrants into these neighborhoods. This is particularly likely in the Belgian context, characterized by a liberal housing market with few available public dwellings. In this regard the findings may be specific for Belgium and could operate differently in countries where housing markets work in another way and in which for example public housing is more important. Comparative (cross country) studies are needed to assess these patterns and the role of the housing market further.

Our analyses also illustrated how neighborhood boundaries are similar at the micro-, meso- and macro-levels for some migrant populations. We found evidence of some groups sharing the same urban space (for example Turks and Eastern Europeans in Ghent) while others reside completely separate from one another (for example Western Europeans and Moroccans in Brussels). This suggests a certain ethnic hierarchy between groups (in line with social-psychological studies; e.g. Hraba, Hagendoorn, \& Hagendoorn, 1989; Kandylis, Maloutas, \& Sayas, 2012). The strong gravitational force towards particular urban segments, wherein migrant populations who are equally positioned in the hierarchy are overrepresented in nearly all micro-neighborhoods, highlights the importance of structural and institutional forces (i.e. place stratification theory) or, conversely, the role of individual agency (i.e. self-selection into ethnic communities). Although the residual housing market in cities is likely to have shaped the residential opportunities and restrictions of migrants to some extent, we are not able to draw firm conclusions about this based on our analyses (as we lack indicators to study this directly). From the nearest neighbors' perspective, one can however expect that in the context of ethnic diversification of population, the between group contacts are likely to increase, conditional on whether these groups share the same neighbors. Conversely, it suggests a living next to each other of different groups where those of different origins and different socio-economic background hardly meet. This segmentation between groups can have major implications for individual life outcomes but also for cohesion in the society at large. 
Moreover, even if immigrant populations live more dispersed across the city, small clusters can still emerge (Musterd, 2005). We find that to be the case for Eastern Europeans, Turks and Moroccans in Charleroi and for Moroccans in Ghent and Eastern Europeans in Brussels for example. Albeit pronounced concentration areas at the macrolevel, micro-neighborhood concentrations of these ethnic groups tend to be more dispersed throughout the city, suggesting partial spatial assimilation. These scale dependent patterns to some extent were reflected in a firm decrease of isolation with increasing scale, particularly in Charleroi. Whether this results from a low-cost housing being available throughout the city, better spatial integration, or whether it is a matter of precarious subgroups facing more enforced segregation or segregated themselves voluntary, is hard to conclude based on our data. More in-depth analysis covering other aspects which are not possible to analyze with our data at hand, is needed to understand the processes behind the scale-dependent patterns as well as the potential factors that facilitate more ethnic mixing. In exploring the LQ among 50 or 100 nearest neighbors versus higher order $k$-values, our method provides empirical evidence that microneighborhoods of significant overrepresentation remain unnoticed when using predefined areal units (i.e. statistical sectors). This calls for more detailed analyses as a way ahead to understand the complex interplay between geography and ethnic concentration.

Proponents of the 'multicultural' perspective argue that minority enclaves are the result of voluntary self-segregation. Especially in larger cities, such as Brussels, ethnic clustering is suggested to provide potential benefits and create mutual support through the proximity of family and friends, social and ethnic networks, cultural provision and services, and for the development of ethnic entrepreneurship, institutions and businesses (Van der Laan Bouma-Doff, 2007). Since our study only considers first-generation migrants, self-segregation is potentially overestimated. In support of this, is the recent suburbanization processes that have been found among migrant groups (de Valk \& Willaert, 2012), which could point towards a very slow or delayed spatial integration. All in all, it is plausible to assume that the often precarious socio-economic position of 'newly' arrived migrants makes them highly dependent of those already present in the host country. Nevertheless, from our analyses, it seems that, irrespective of the extent to which migrants sort themselves into neighborhoods, residential avoidance of the native population with regards to ethnic enclaves, contributes significantly to the observed spatial separation at any geographical scale. The extent, however, to which the existence of pronounced concentrations areas using multiscalar individualized neighborhoods 
ceteris paribus then enhances an increased potential for being attractive among the respective ethnic groups or heightens native outmigration, would be a valuable future extension to our work.

Despite the contributions we have made in this article, some limitations need to be mentioned. First, our analysis does not allow to draw conclusions on the underlying mechanisms that cause segregation, nor does it make any statements on the potential outcomes of segregation. Nonetheless, it underlines the multiscalar nature of segregation, which should be considered in research on spatial fragmentation. It also cautions against generalizations of people and places. Second, the socio-economic deprivation of minority populations is deeply rooted within the urban spatial structure in Belgium and, therefore, might blur the interpretation of ethnic geographies (Musterd, 2005). Hence, we suggest ethnic and socio-economic indicators to be considered simultaneously in future studies. Third, our focus on first-generation migrants tends to simplify reality. In this way we don't do justice to the growing share of those of migrant origin that were born in Belgium but may still face ethnic segregation. Also, given that dynamic processes underlie ethnic geographies (Simpson, 2005), (the lack of) social and residential integration of different generations of migrant origin in our analyses may either result in an under- or overestimation of segregation. Fourth, ideally, individual geocoded data should be used if we want to avoid any MAUP related issues. The use of grids as we did in this study still involves the implicit assumption that individuals who live near one another but in different areal units, are more distant from each other than those living on opposite sides in the same spatial unit (Reardon \& O'Sullivan, 2004). Regardless, the use of 200x200m grids was needed to balance out low counts for some ethnic groups in some neighborhoods. The likelihood of excluding the more distant individuals from outside the city when pooling neighborhood populations therefore increases with an increasing $k$. Even though this issue remains problematic for grid populations near water and woods (e.g. the Zoniën-forest in Brussels, the harbor of Antwerp and Ghent), industrial sites (e.g. in Charleroi) or in border areas (e.g. Antwerp), the overall densely populated geography of Belgium in this sense limits potential large bias. Finally, the utilization of scalable egocentric neighborhoods does not provide an ideal scale of segregation measurement, nor does it identify what it is exactly that a neighborhood means to its inhabitants or to others. Future research on ethnic geographies and segregation should further explore the $k$-nearest neighbors approach in evaluating the causes and consequences of segregation in urban and rural areas. 
To sum up, this study illustrated the variability of ethnic segregation between migrant origin groups, places and scale by using individualized neighborhoods. We revealed some important patterns using full population data on Belgium and showed that an ethnic-, location- and scale-specific approach is indispensable to advance our understanding on ethnic geographies and segregation. This could be a stimulating starting point for further work on comparisons across other European countries with different migration histories, housing policies and settlement patterns. By carrying the work in this field further, we can start understanding how segregation is impacting individual lives and life outcomes.

\section{Funding}

This work was supported by Research Foundation Flanders [Aspirant Fonds Wetenschappelijk Onderzoek Vlaanderen (Belgium)] under grant number FWOTM670. The work of the third author was part of and financed by the JPI Urban Europe ResSegr project "Residential segregation in five European countries- a comparative study using individualized scalable neighbourhoods".

\section{Acknowledgments}

We thank the anonymous referees for their useful comments and suggestions on earlier versions of the paper. Additionally, we thank Statistics Belgium for preparing and providing the geocoded census data.

\section{Disclosure statement}

The authors have no potential conflict of interest to declare. 


\section{References}

Ainsworth, James W. (2002). Why does it take a village? The mediation of neighborhood effects on educational achievement. Social Forces, 81(1), 117-152.

Andersson, Roger, \& Musterd, Sako (2005). Area-based policies: A critical appraisal. Tijdschrift voor Economische en Sociale Geografie, 96(4), 377-389.Bailey, Nick (2012). How spatial segregation changes over time: Sorting out the sorting processes. Environment and Planning A, 44(3), 705-722.

Bajari, Patrick, \& Kahn, Matthew E. (2005). Estimating housing demand with an application to explaining racial segregation in cities. Journal of Business and Economic Statistics, 23(1), 19-33.

Bolster, Anne, Burgess, Simon, Johnston, Ron, Jones, Kelvyn, Propper, Carol, \& Sarker, Rebecca (2007). Neighborhoods, households and income dynamics: A semiparametric investigation of neighborhood effects. Journal of Economic Geography, 7(1), 1-38.

Bolt, Gideon (2009). Combating residential segregation of ethnic minorities in European cities. Journal of Housing and the Built Environment, 24(4), 397-405.

Brown, Lawrence A., \& Chung, Su-Yeul (2006). Spatial segregation, segregation indices and the geographical perspective. Population, Space and Place, 12(2), 125-143.

Calliez, Julie (2009). De l'espace des flux à l'espace des lieux: Pour une transmission de savoir-faire spatiaux [From the space of flows towards the space of places: For a transmission of spatial know-how]. In Nathalie Burnay \& Annabelle Klein (Eds.), Figures contemporaines de la transmission [Contemporary figures of transmission] (pp. 43-57). Namur: Presses universitaires de Namur, collection Transhumances.

Castles, Stephen (2006). Guestworkers in Europe: A resurrection? International Migration Review, 40(4), 741-766.

Catney, Gemma (2016). The changing geographies of ethnic diversity in England and Wales, 1991-2011. Population, Space and Place, 22(8), 750-765.

de la Rica, Sara, Glitz, Albrecht, \& Ortega, Francesc (2015). Immigration in Europe: Trends, policies and empirical evidence. In Barry R. Chiswick \& Paul W. Miller (Eds.), Handbook of the economics of international migration, Volume 1 (pp. 13031362). North Holland: Elsevier.

de Valk, Helga A.G., \& Willaert, Didier (2012). Internal mobility of international migrants: the case of Belgium. In Nissa Finney \& Gemma Catney (Eds.), Minority internal migration in Europe (pp.13-38). Surrey: Ashgate. 
Dustmann, Christian, \& Frattini, Tommaso (2011). Immigration: The European experience (IZA Discussion Paper No. 6261). Retrieved from IZA Institute of Labor Economics: http://ftp.iza.org/dp6261.pdf

Fowler, Christopher S. (2016). Segregation as a multiscalar phenomenon and its implications for neighborhood-scale research: The case of South Seattle 1990-2010. Urban Geography, 37(1), 1-25.

Galster, George (2001). On the nature of neighbourhood. Urban Studies, 38(12), 21112124.

Hraba, Joseph, Hagendoorn, Louk, \& Hagendoorn, Roeland (1989). The ethnic hierarchy in the Netherlands: Social distance and social representation. Social Psychology, 28(1), 57-69.

Johnston, Ron, Poulsen, Michael, \& Forrest, James (2002). Rethinking the analysis of ethnic residential patterns: Segregation, isolation, or concentration thresholds in Auckland, New Zealand? Geographical Analysis, 34(3), 245-261.

Johnston, Ron, Poulsen, Michael, \& Forrest, James (2004). The comparative study of ethnic residential segregation in the USA, 1980-2000. Tijdschrift voor Economische en Sociale Geografie, 95(5), 550-569.

Johnston, Ron, Poulsen, Michael, \& Forrest, James (2007). Ethnic and residential segregation in U.S. metropolitan areas, 1980-2000: The dimensions of segregation revisited. Urban Affairs Review, 42(2), 479-504.

Johnston, Ron, Forrest, James, Jones, Kelvyn \& Manley, David (2016). The scale of segregation: Ancestral groups in Sydney, 2011. Urban Geography, 37(7), 985-1008.

Jones, Kelvyn, Johnston, Ron, Manley, David, Owen, Dewi, \& Charlton, Chris (2015). Ethnic residential segregation: A multilevel, multigroup, multiscale approach exemplified by London in 2011. Demography, 52(6), 1995-2019.

Kandylis, George, Maloutas, Thomas, \& Sayas, John (2012). Immigration, inequality and diversity: Socio-ethnic hierarchy and spatial organisation in Athens, Greece. European Urban and Regional Studies, 19(3), 267-286.

Kaplan, David H., \& Woodhouse, Kathleen (2005). Research in ethnic segregation II: Measurements, categories and meanings. Urban Geography, 26(8), 737-745.

Kearns, Ade \& Parkinson, Michael (2001). The significance of neighbourhood. Urban Studies, 38(12), 2103-2110.

Kesteloot, Christian, \& Cortie, Cees (1998). Housing Turks and Moroccans in Brussels and Amsterdam: The difference between private and public markets. Urban Studies, 
35(10), 1835-1853.

Khoojinian, Mazyar (2006). L'Accueil et la stabilisation des travailleurs immigrés turcs en Belgique, 1963-1980 [Reception and stabilization of Turkish immigrant workers in Belgium, 1963-1980]. Cahiers d'Histoire Du Temps Présent, 17, 73-116.

Lee, Barrett A., Reardon, Sean F., Firebaugh, Glenn, Farrell, Chad R., Matthews, Stephen A., \& O'Sullivan, David (2008). Beyond the census tract: Patterns and determinants of racial segregation at multiple geographic scales. American Sociological Review, 73(5), 766-791.

MacAllister, Iain, Johnston, Ron, Pattie, Charles, Tunstall, Helena, Dorling, Danny, \& Rossiter, David (2001). Class dealignment and the neighbourhood effect: Miller Revisited. British Journal of Political Science, 31(1), 41-59.

Marcińczak, Szymon, Musterd, Sako, van Ham, Maarten, \& Tammaru, Tiit (2015). Inequality and rising levels of socio-economic segregation. Lessons from a panEuropean comparative study. In Tiit Tammaru, Maarten van Ham, Szymon Marcińczak, \& Sako Musterd (Eds.), Socio-economic segregation in European capital cities - East meets West (1st ed.) (pp. 358-382). London: Routledge.

Massey, Douglas S. (1985). Ethnic residential segregation: A theoretical synthesis and empirical review. Sociology and Social Research, 69(3), 315-350.

Massey, Douglas S., \& Denton, Nancy A. (1988). The dimensions of residential segregation. Social Forces, 67(2), 281-315.

Musterd, Sako (2003). Segregation and integration: A contested relationship. Journal of Ethnic and Migration Studies, 29(4), 623-641.

Musterd, Sako (2005). Social and ethnic segregation in Europe: Levels, causes, and effects. Journal of Urban Affairs, 27(3), 331-348.

Openshaw, Stan (1984). The modifiable areal unit problem: Concepts and techniques in modern geography. Number 38. Norwich: Geo Books.

Östh, John (2014). EquiPop [Computer Software]. Uppsala: John Östh.

Östh, John, Clark, William A.V., \& Malmberg, Bo (2015). Measuring the scale of segregation using k-nearest neighbor aggregates. Geographical Analysis, 47(1), 3449.

Östh, John, Malmberg, Bo \& Andersson, Eva K. (2014). Analysing segregation using individualized neighbourhoods. In Chris Lloyd, Ian G. Shuttleworth, \& David W.S. Wong (Eds.), Socio-spatial segregation: Concepts, processes and outcomes (pp. 135-162). Bristol: Policy Press. 
O'Sullivan, David \& Wong, David W.S. (2007). A surface-based approach to measuring spatial segregation. Geographical Analysis, 39(2), 147-168.

Phalet, Karen, \& Swyngedouw, Marc (2003). Measuring immigrant integration: The case of Belgium. Migration Studies, 40(152), 773-804.

Reardon, Sean F., Matthews, Stephen A., O’Sullivan, David, Lee, Barrett A., Firebaugh, Glenn, Farrell, Chad R., \& Bischoff, Kendra (2008). The geographic scale of metropolitan racial segregation. Demography, 45(3), 489-514.

Reardon, Sean F., \& O’Sullivan, David (2004). Measures of spatial segregation. Sociological Methodology, 34(1), 121-162.

Sharkey, Patrick \& Faber, Jacob W. (2014). Where, when, why, and for whom do residential contexts matter? Moving away from the dichotomous understanding of neighborhood effects. Annual Review of Sociology, 40, 559-579.

Simpson, Ludi (2005). On the measurement and meaning of residential segregation: A reply to Johnston, Poulsen and Forrest. Urban Studies, 42(7), 1229-1230.

Statistics Belgium (2015). Census 2011 Belgium, Geo-coded grid-data (200x200m).

Tajfel, Henri, \& Turner, John C. (1979). An integrative theory of intergroup conflict. In William G. Austin \& Stephen Worchel (Eds.), The social psychology of intergroup relations (pp. 33-48). Monterey, CA: Brooks-Cole.

Van der Haegen, Herman, Brulard, Théo, Kesteloot, Christian \& Vanneste, Dominique (1992). De steden [The cities]. In Jacques Denis (Ed.), Geografie van België [Geography of Belgium] (pp. 427-482). Brussels: Gemeentekrediet.

Van der Laan Bouma-Doff, Wendy (2007). Involuntary isolation: Ethnic preferences and residential segregation. Journal of Urban Affairs, 29(3), 289-309.

van Ham, Maarten \& Tammaru, Tiit (2016). New perspectives on ethnic segregation over time and space. A domains approach. Urban Geography, 37(7), 953-962.

Van Hamme, Gilles, Wertz, Isaline, \& Biot, Valérie (2011). Economic growth devoid of social progress: the situation in Brussels. Brussels Studies, 48, 1-18.

van Kempen, Ronald, \& Wissink, Bart (2014). Between places and flows: Towards a new agenda for neighbourhood research in an age of mobility. Geografiska Annaler: Series B, Human Geography, 96(2), 95-108.

Van Mol, Christophe, \& de Valk, Helga A.G. (2016). Integration processes and policies in Europe: A historical and demographic perspective. In Blanca Garcès-Mascarenas \& Rinus Penninx (Eds.), Integration processes and policies in Europe (pp. 31-55). Rotterdam: Springer. 
Wong, David W.S. (2004). Comparing traditional and spatial segregation measures: A spatial scale perspective. Urban Geography, 25(1), 66-82.

Zorlu, Aslan, \& Mulder, Clara H. (2008). Initial and subsequent location choices of immigrants to the Netherlands. Regional Studies, 42(2), 245-264. 
Appendix 1. Belgium's migration history at a glance.

Compared to the transatlantic immigration history, large scale immigration is a quite recent and heterogeneous phenomenon in EU-countries including Belgium (Dustmann \& Frattini, 2011). It is the advent of mass immigration after nation building, that sets Western European countries apart from a traditional country of longstanding immigration, such as the United States. The $21^{\text {st }}$ century European landscape is diffused and reveals specific particularities as a consequence of migration law and (lacking) integration policies. Three particular eras of migration can be discerned within the European and Belgian context (for a detailed description, we refer to Van Mol \& de Valk (2016)). A first period covers the period between the end of the Second World War and 1974. After the economic recession of the 1930's and the associated drop back in labor migration, the prosperous decades after WWII compelled the establishment of policy based interventions regarding international migration through inter-state agreements that were aimed at filling the acute shortages in the labor market (heavy industry) that emerged throughout the 1950's (Rica et al., 2015). The recruitment of labor during the inter-bellum mainly started in peripheral countries. Later on, labor migrants were also recruited in Italy since 1946, in Spain since 1956, in Greece since 1957, in Turkey and Morocco since 1964, in Tunisia since 1969, in Algeria and former Yugoslavia since 1970. These bilateral conventions provided a flexible work-permit regime and lenient family reunification rules (Khoojinian, 2006). Alongside, an inflow of people from the colony of Congo after independence in 1960 was observed. These flows included both Belgian returnees as well as Congolese student migration to Belgium. The trente glorieuses came to an end with the oil crisis in 1973-1974 and resulted in an official halt in the recruitment of labor migrants due to the sharp increase in unemployment, thereby shifting from labor migration towards migration driven by family reunification and marriage from the 1980's onwards (Dustmann \& Frattini, 2011). Consequently, former temporary cheap and often poorly educated labor migrants were to stay. Meanwhile, free movement of people and goods was enabled through the foundation and gradual expansion of the European Economic Community (later on European Union) (Dustmann \& Frattini, 2011). While family reunification and marriage migration continued, the influx of foreigners diversified greatly. This second period ends in the late 1980's. Since the 1990's to 2012 (period three), the group of newcomers expanded with highly skilled employees, international students, asylum seekers and refugees (i.e. from former Yugoslavia, former communist countries, the Middle-East and Central Sub-Saharan Africa). Accompanied by new EU policies directed at labor migration, a new influx of citizens from new EU member states was observed since 2004 (Cyprus, Czech Republic, Estonia, Hungary, Latvia, Lithuania, Malta, Poland, Slovakia and Slovenia) and 2007 (Bulgaria and Romania) (Castles, 2006). 
Appendix 2. Spatial distribution of Location Quotients of Moroccan foreign-born in the BrusselsCapital Region (BCR), Ghent and Charleroi, using individualized neighborhoods containing the 50,800 and 6,400 nearest neighbors, $1 / 1 / 2011$.

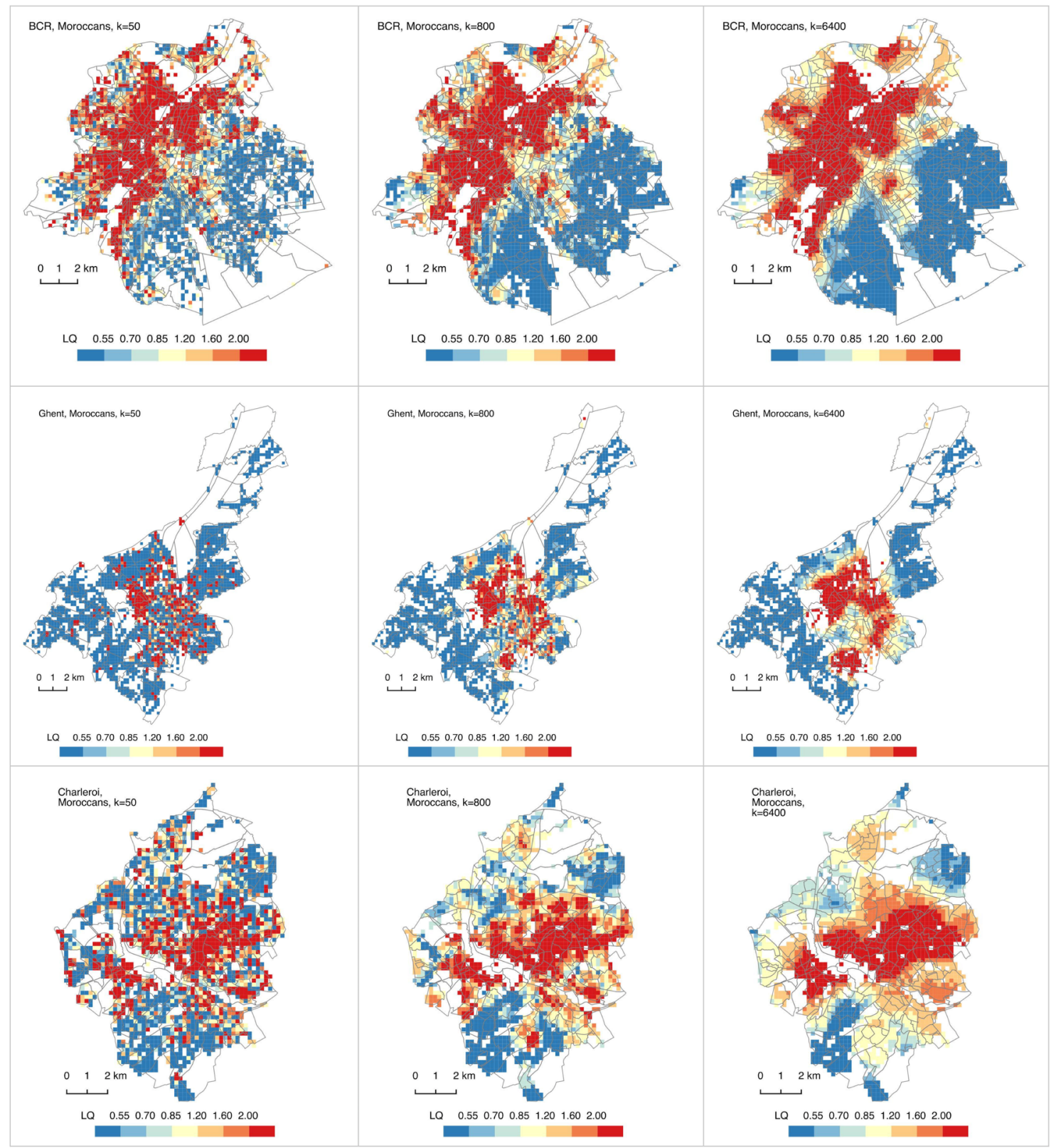

Source: Census 2011, authors' calculations using EquiPop 
Appendix 3. Spatial distribution of Location Quotients of Western, Southern and Eastern European foreign-born in Antwerp, Liège and Charleroi respectively, using individualized neighborhoods containing the 50,800 and 12,800 nearest neighbors, 1/1/2011.

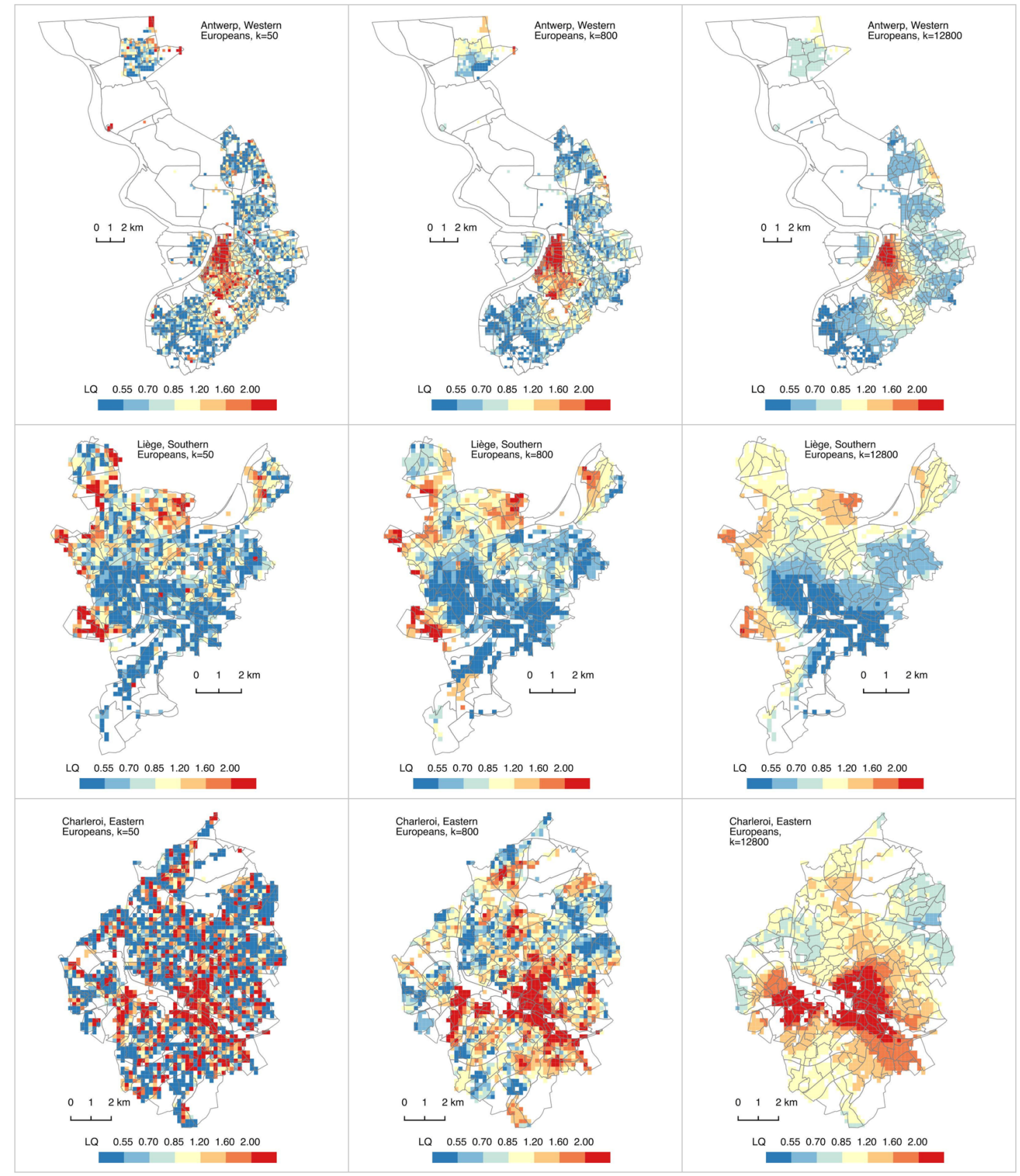

Source: Census 2011, authors' calculations using EquiPop 
Appendix 4. Spatial distribution of Location Quotients of Eastern and Southern European foreign-born in Ghent and Charleroi respectively, using individualized neighborhoods containing the 50,800 and 6,400 nearest neighbors, $1 / 1 / 2011$

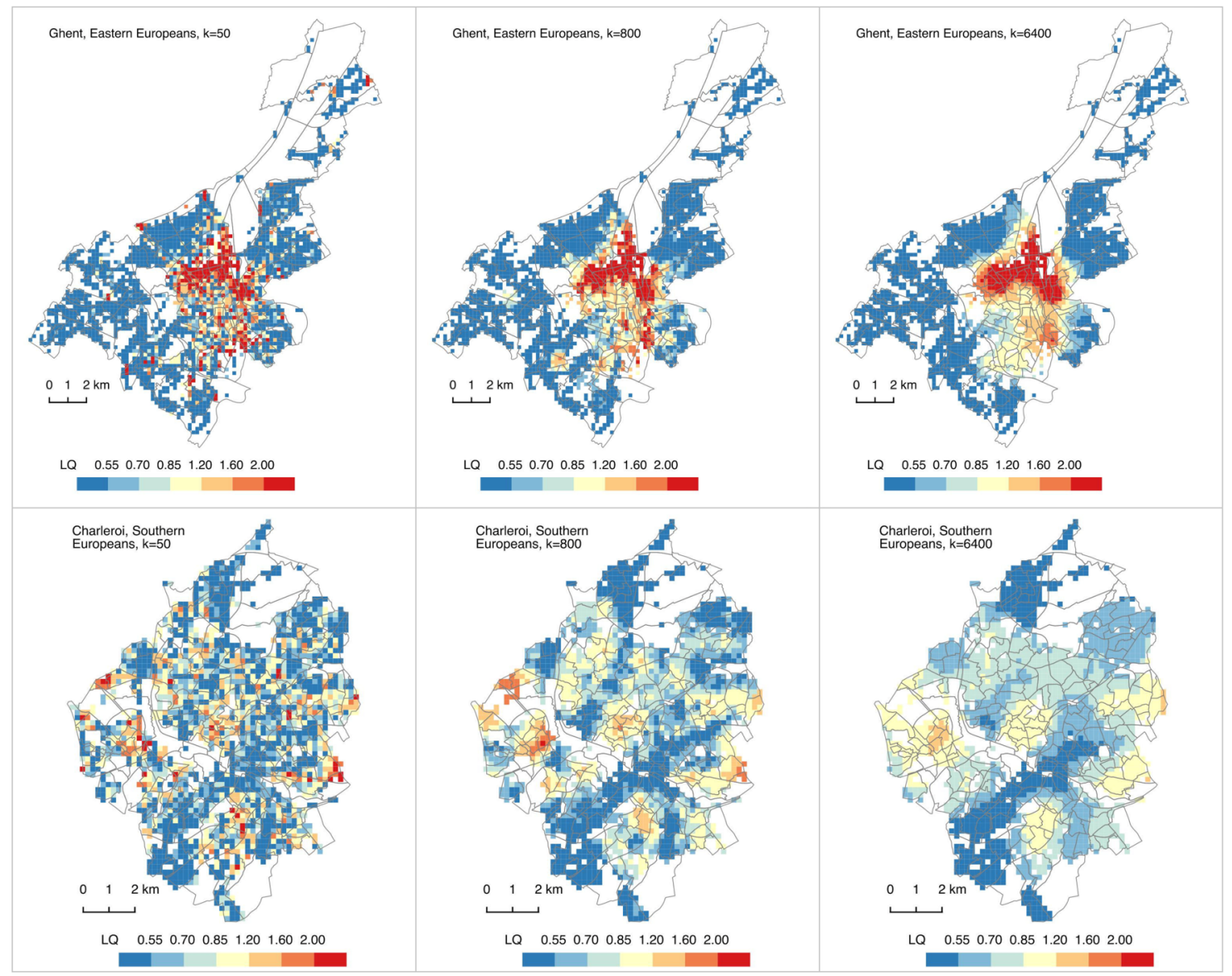

Source: Census 2011, authors' calculations using EquiPop 